$$
\text { Pontifícia Universidade } \text { CATÓLICA }_{\text {DO RIO DE JANERO }}
$$

Gisele Cristina da Cunha Holtz

Traçado automático de envoltórias de esforços em estruturas planas utilizando um algoritmo evolucionário

Dissertação de Mestrado

Dissertação apresentada como requisito parcial para obtenção do título de Mestre pelo Programa de PósGraduação em Engenharia Civil da PUC-Rio.

Orientadores: Luiz Fernando C. R. Martha Luiz Eloy Vaz 


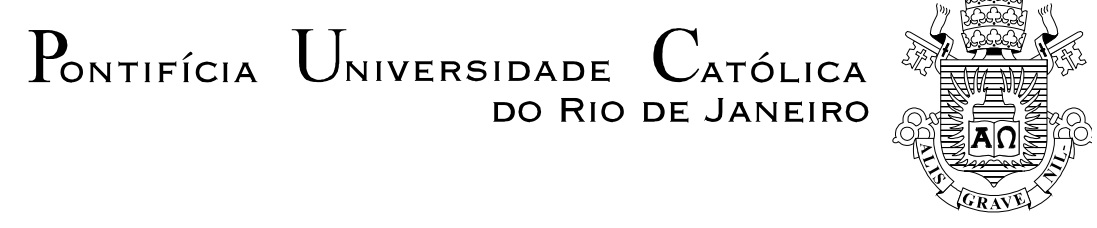

Gisele Cristina da Cunha Holtz

\section{Traçado automático de envoltórias de esforços em estruturas planas utilizando um algoritmo evolucionário}

Dissertação apresentada como requisito parcial para obtenção do título de Mestre pelo Programa de Pós-Graduação em Engenharia Civil da PUC-Rio. Aprovada pela Comissão Examinadora abaixo assinada.

Luiz Fernando Campos Ramos Martha Presidente / Orientador Departamento de Engenharia Civil - PUC-Rio

Luiz Eloy Vaz

Co-orientador

UFRJ

Raul Rosas e Silva

Departamento de Engenharia Civil - PUC-Rio

Ivan Fábio Mota de Menezes Departamento de Informática - PUC-Rio

Pedro Colmar Gonçalves da Silva Vellasco

UERJ

José Eugênio Leal

Coordenador(a) Setorial do Centro Técnico Científico - PUC-Rio

Rio de Janeiro, 14 de abril de 2005 
Todos os direitos reservados. É proibida a reprodução total ou parcial do trabalho sem autorização da universidade, da autora e do orientador.

\section{Gisele Cristina da Cunha Holtz}

Graduou-se em Engenharia Civil, pelo UniFOA - Centro Universitário de Volta Redonda em 2002. Desenvolveu seu trabalho de pesquisa com ênfase em computação gráfica aplicada.

Ficha Catalográfica

Holtz, Gisele Cristina da Cunha

Traçado automático de envoltórias de esforços em estruturas planas utilizando algoritmo evolucionário / Gisela Cristina da Cunha Holtz ; orientador: Luiz Fernando C. R. Martha, Luiz Eloy Vaz. - Rio de Janeiro : PUC, Departamento de Engenharia Civil, 2005.

$$
\text { v., } 123 \text { f. : IL. ; } 29,7 \mathrm{~cm}
$$

Dissertação (mestrado) - Pontifícia Universidade Católica do Rio de Janeiro, Departamento de Engenharia Civil.

Inclui referências bibliográficas.

1. Engenharia civil - Teses. 2. Estratégia evolutiva. 3. Computação evolucionária. 4. Envoltória de esforços internos. 5. Trem-tipo. I. Martha, Luiz Fernando Campos Ramos. II . Vaz, Luiz Eloy. III. Pontifícia Universidade Católica do Rio de Janeiro. Departamento de Engenharia Civil. IV. Título. 


\section{Agradecimentos}

A Deus, pela certeza de Seu amor incondicional.

Aos meus pais, Osmar e Fátima, que não mediram esforços para tornar possível a concretização desta etapa, dando todo o apoio, carinho e incentivo necessários.

Ao meu marido Júlio, pelo companherismo, amor e paciência inestimáveis, que tornaram mais ameno e agradável o tempo dedicado à conclusão deste trabalho.

Ao meu irmão Gustavo, pela amizade e incentivo, e a minha irmã Patrícia, pelos cuidados e carinhos de uma verdadeira mãe.

Ao professor Luiz Fernando Martha, orientador deste trabalho, pela confiança que me dedicou, pela qualidade de seus ensinamentos e pela eficiência ao orientar este trabalho.

Ao professor Luiz Eloy Vaz, co-orientador deste trabalho, pelo direcionamento do caminho a seguir no desenvolvimento deste trabalho e por suas valiosas orientações.

Aos professores Francisco Abreu, Nacib Abdala e Ildony Bellei, que foram os primeiros a me incentivar a seguir este caminho.

A todos os amigos e familiares pelas orações e pelo incentivo, em especial ao meu avô João Batista e a amiga Laci Tuller, que acompanharam de perto as dificuldades enfrentadas, e aos novos amigos aqui conquistados, Juliana Vianna, Patrício Pires e Leandro Ferreira.

Aos amigos do TecGraf que muito contribuíram, direta ou indiretamente, para o desenvolvimento deste trabalho.

À Ana Roxo e a todos os funcionários e professores do Departamento de Engenharia Civil da PUC.

Ao TecGraf pelo apoio financeiro e tecnológico durante o curso de mestrado.

À CAPES pelo apoio financeiro durante o curso de mestrado. 


\section{Resumo}

Holtz, Gisele Cristina da Cunha; Martha, Luiz Fernando C. R. (Orientador); Vaz, Luiz Eloy (Co-orientador). Traçado automático de envoltórias de esforços em estruturas planas utilizando um algoritmo evolucionário. Rio de Janeiro, 2005. 123p. Dissertação de Mestrado - Departamento de Engenharia Civil, Pontifícia Universidade Católica do Rio de Janeiro.

O objetivo deste trabalho é desenvolver dentro do programa FTOOL uma ferramenta para obtenção de envoltórias de esforços internos devido a cargas móveis. Envoltórias geralmente são obtidas através de interpolação de valores limites de seções pré-selecionadas ao longo da estrutura. Estes valores são obtidos com base no posicionamento da carga móvel em relação às linhas de influência dos esforços internos. A determinação de valores limites de um esforço em uma seção constitui um problema de otimização cujo objetivo é minimizar ou maximizar os valores dos esforços em relação à posição do tremtipo que percorre a estrutura. Porém, não existe uma expressão analítica que defina os valores limites de um esforço em uma seção para um dado trem-tipo, o que impossibilita o uso da maioria dos métodos clássicos de otimização para resolver o problema, porque esses métodos requerem, na maioria das vezes, o uso de pelo menos a primeira derivada da função objetivo em relação às variáveis de projeto. Portanto, este trabalho adotou algoritmos da Estratégia Evolutiva ( $E E$ ) para determinar os valores limites devidos a cargas móveis. Foram feitas duas implementação distintas de Estratégia Evolutiva, conhecidas como $(1+\lambda)-E E$ e $(\mu+\lambda)-E E$. Além de utilizar algoritmos de $E E$ para resolver o problema de envoltórias, foi desenvolvido um outro processo de solução denominado Força Bruta, que consiste em percorrer com o trem-tipo toda estrutura por passos pré-estabelecidos e calcular os valores dos esforços mínimos e máximos. Para a grande maioria dos casos, os resultados obtidos com a Estratégia Evolutiva foram corretos, porém, em alguns casos mais críticos, o valor exato da envoltória não é encontrado em algumas seções da estrutura, embora encontre um valor muito próximo a ele. Observou-se que os resultados da $E E$ podem ser melhorados quando se enriquece a solução com uma estratégia econômica de posicionamento de cargas concentradas em cima de picos da linha de influência.

\section{Palavras-chave}

Estratégia Evolutiva, Computação Evolucionária, Envoltória de Esforços Internos, Trem-tipo. 


\section{Abstract}

Holtz, Gisele Cristina da Cunha; Martha, Luiz Fernando C. R. (Advisor); Vaz, Luiz Eloy (Co-advisor). Automatic tracing of envelopes in planar structures using a evolutionary algorithm. Rio de Janeiro, 2005. 123p. MSc. Dissertation - Civil Engineering Department, Pontifícia Universidade Católica do Rio de Janeiro.

The objective of this work is to develop a tool for obtaining envelopes of internal forces due to load-trains in the FTOOL software. Usually, envelopes are obtained through interpolation of limiting values on pre-selected sections along the structure. These values are obtained based on the positioning of the loadtrain in relation to influence lines of internal forces. The determination of limiting values of an effect at a section represents an optimization problem whose objective is to minimize or maximize the values of that effect in relation to the position of a load-train that passes along the structure. However, there is no analytical expression that defines a limiting value of an effect on a section for a specific load-train. Therefore, classical optimization methods cannot be used to solve this problem. Rather, the solution requires a method that does not require derivatives of the objective function. For this reason, this work adopts algorithms of the Evolution Strategy (ES) to achieve the limiting values due to load-trains. Two distinct algorithms of the ES, known as $(1+\lambda)-E S$ and $(\mu+\lambda)-E S$, were implemented. In addition to the ES algorithms to trace the envelopes, another process of solution called Brute Force was developed. It consists of moving the load-train in pre-determined steps along the structure and calculating minimum e maximum values. In general, the ES method converges to the correct solution. However, there are cases, depending on the complexity of the load-train, that the algorithms do not find the exact limiting value (although usually very close to it). It was observed that the ES results could be complemented and improved with results from an inexpensive solution in which concentrated loads are positioned on peak values of the influence lines.

\section{Key-words}

Evolution Strategy, Evolutionary Computation, Envelopes of Internal Forces, Load-Train. 


\section{Sumário}

1 Introdução 20

1.1. Objetivo 20

1.2. Organização do Trabalho 21

2 Cargas Móveis, Linhas de Influência e Envoltórias de Esforços 22

2.1. Introdução 22

2.2. Classificação das ações atuantes nas estruturas 22

2.3. Cargas Móveis 23

2.4. Linhas de Influência 24

2.4.1. Traçado de LI 25

2.5. Determinação de esforço extremo com base em LI 26

2.6. Envoltória Limite de Esforços 28

3 Métodos de Otimização $\quad 35$

3.1. Introdução $\quad 35$

3.2. Definições

3.3. Métodos Determinísticos 36

3.4. Métodos Probabilísticos 38

3.4.1. Computação Evolucionária 38

3.4.1.1. Definições 41

3.4.1.2. Algoritmo Evolucionário 41

3.4.1.3. Principais Ramos da Computação Evolucionária 46

3.4.1.4. Algoritmos Genéticos (AG's) $\quad 47$

3.4.1.5. Programação Genética $(P G) \quad 48$

3.4.1.6. Programação Evolutiva (PE) 50

3.4.1.7. Estratégia Evolutiva (EE) 51

3.4.1.7.1. Distribuição Normal 52

3.4.1.7.2. Algoritmo Padrão de EE 55

3.4.1.8. Comparação entre Estratégia Evolutiva e Algoritmo Genético 57

4 Implementação Computacional $\quad 59$

4.1. Introdução 59 
4.2.1. NBR - 7188 - Carga móvel em ponte rodoviária e passarela de pedestre

4.2.2. NBR - 7189 - Cargas móveis para projetos estrutural de obras ferroviárias

4.2.3. Interface gráfica

4.2.4. Carga Concentrada 65

4.2.5. Carga Distribuída 65

4.2.6. Carga de Multidão 67

4.2.7. Estrutura de Dados 69

4.3. Função Aptidão 70

4.3.1. Eventos $\quad 71$

4.3.1.1. Estrutura de Dados dos Eventos 72

4.3.2. Cálculo da Função Aptidão 75

4.3.3. Envoltória de Esforços no FTOOL 75

5 Algoritmos Implementados $\quad 78$

5.1. Introdução $\quad 78$

5.2. Considerações gerais 78

5.3. Estratégia $1+\lambda-E E \quad 80$

5.3.1. Sub-divisão do Espaço de busca 80

5.3.1.1. Estrutura de dados 81

5.3.1.2. Inicialização da população 82

5.3.1.3. Mutação $\quad 82$

5.3.1.4. Seleção 83

5.3.1.5. Critério de parada 85

5.4. Estratégia $\mu+\lambda-E E \quad 85$

5.4.1. Estrutura de dados 85

5.4.1.1. Inicialização da população 86

5.4.1.2. Mutação 86

5.4.1.3. Seleção 86

5.4.1.4. Critério de parada 88

5.5. Força Bruta $\quad 89$

5.6. Cargas-em-picos 90

6 Exemplos de Validação e Análise de Resultados 91 
6.1. Introdução 91

6.2. Exemplo 1

6.2.1. Envoltória de Esforço Cortante 92

6.2.1.1. Variação dos Parâmetros 96

6.2.2. Envoltória de Momento Fletor 98

6.3. Exemplo $2 \quad 100$

6.3.1. Envoltória de Esforço Cortante 100

6.3.2. Envoltória de Momento Fletor 102

6.4. Exemplo $3 \quad 104$

6.4.1. Envoltória de Esforço Normal 105

6.4.2. Envoltória de Esforço Cortante 106

6.4.3. Envoltória de Momento Fletor 108

6.5. Exemplo $4 \quad 109$

6.5.1. Envoltória de Esforço Cortante 110

6.5.2. Envoltória de Momento Fletor 111

6.6. Testes Realizados 113

6.6.1. Caso $1 \quad 113$

6.6.2. Caso $2 \quad 115$

6.7. Análise do número de avaliações da função aptidão 116

6.8. Análise do tempo de processamento 117

7 Conclusão 119

7.1. Sugestão para trabalhos futuros $\quad 120$

$\begin{array}{ll}\text { Referência Bibliográfica } & 121\end{array}$ 


\section{Lista de figuras}

Figura 2.1 - Linha de influência de momento fletor em uma seção de uma viga contínua. 24

Figura 2.2 - Deslocamentos generalizados utilizados no método cinemático. 26 Figura 2.3- Carga permanente uniformemente distribuída atuando em uma viga contínua.

Figura 2.4 - Posicionamento da carga móvel para provocar máximo momento fletor em uma seção.

Figura 2.5 - Posicionamento da carga móvel para provocar mínimo momento fletor em uma seção.

Figura 2.6 - Viga bi-apoiada com balanços, carga permanente e carga móvel. 29

Figura 2.7 - Esforços internos da carga permanente.

Figura 2.8 - Esforço cortante máximo e mínimo na seção $B^{\text {esq }}$. 30

Figura 2.9 - Esforço cortante máximo e mínimo na seção $B^{\text {dir }}$. 30

Figura 2.10 - Esforço cortante máximo e mínimo na seção $C$. 30

Figura 2.11 - Esforço cortante máximo e mínimo na seção $D$. 31

Figura 2.12 - Envoltórias de Esforço Cortante. 32

Figura 2.13 - Momento fletor máximo e mínimo na seção $B$. 32

Figura 2.14 - Momento fletor máximo e mínimo na seção $C$. 32

Figura 2.15 - Momento fletor máximo e mínimo na seção $D$. 33

Figura 2.16 - Envoltórias de momento fletor. 33

Figura 3.1- Formulação de um problema de otimização. 37

Figura 3.2 - Evolução típica de um $A E$, ilustrada de acordo com a distribuição da população. Adaptado de EIBEN \& SMITH (2003). 40

Figura 3.3 - Esquema geral de um Algoritmo Evolucionário. Adaptado de BÄCK et al (1997).

Figura 3.4 - Ramificação da Inteligência Artificial. Adaptada de

OLIVIERI (2004). 46

Figura 3.5- Seleção utilizando o método da roleta (Barbosa, 1977). 48

Figura 3.6 - Crossover na $P G$ : seleção aleatória dos ramos que sofrerão o corte (SOUSA \& ANDRADE, 1998).

Figura 3.7 - Crossover na $P G$ : funções resultantes (SOUSA \& ANDRADE, 1998). 
Figura 3.8 - Aplicação do operador de mutação na $P G$

(SOUSA \& ANDRADE, 1998).

Figura 3.9 - Função de densidade de probabilidade de uma v.a. normal com

média $\alpha$ e desvio padrão $\sigma$.

Figura 3.10 - Números gerados pela função rand da biblioteca da linguagem C.54

Figura 3.11- Números gerados pela transformação da v.a. uniforme em v.a.

normal.

Figura 4.1 - Trem-tipo composto de um veículo e de cargas uniformemente distribuídas (NBR - 7188, 1982).

Figura 4.2 - Veículos-tipo (NBR - 7188, 1982).

Figura 4.3 - Características geométricas do trem-tipo (NBR - 7189, 1985).

Figura 4.4 - Interface gráfica para a edição de um novo trem-tipo.

Figura 4.5 - Lista expansível para seleção do trem-tipo. 63

Figura 4.6 - Módulo para edição do nome do trem-tipo. 64

Figura 4.7 - Área destinada à edição do comprimento do trem-tipo. 64

Figura 4.8 - Matriz de cargas concentradas. $\quad 65$

Figura 4.9 - Matriz de cargas distribuídas para trem-tipo rodoviário. 66

Figura 4.10 - Matriz de cargas distribuídas para trem-tipo ferroviário. 66

Figura 4.11 - Cargas de multidão. $\quad 67$

Figura 4.12 - Trecho de uma ponte. 68

Figura 4.13 - $L I$ da reação no apoio $A$, na Seção $I I-I I$. 68

Figura 4.14 - $L I$ da reação no apoio $A$, na Seção $I-I$. 69

Figura 4.15 - Trem-tipo unidimensional resultante da transformação do trem-tipo classe 45 da NBR-7188 (1982). 69

Figura 4.16 - Estrutura de dados do trem-tipo. $\quad 70$

Figura 4.17 - Linha de influência com a identificação dos eventos. 72

Figura 4.18 - Estrutura de dados de um evento 72

Figura 4.19 - Botões para seleção dos esforços. 76

Figura 4.20 - Pórtico com envoltória de esforço cortante devido à ação de uma $\begin{array}{ll}\text { carga móvel } & 76\end{array}$

Figura 4.21 - LI com trem-tipo nas posições críticas. $\quad 77$

Figura 5.1 - Pórtico com viga inclinada, trem-tipo e espaço de busca. $\quad 79$

Figura 5.2 - Determinação do trecho inicial e final. 81

Figura 5.3 - Estrutura de dados dos trechos. 82

Figura 5.4 - Processo de busca por trechos. $\quad 84$

Figura 5.5 - Estrutura de dados de um indivíduo. 85 
Figura 6.1 - Exemplo 1.

Figura 6.2 - Envoltória de esforço cortante do Exemplo 1 para $1+\lambda-E E$, $\mu+\lambda-E E$, Força Bruta e Cargas-em-picos.

Figura 6.3 - LI de Esforço Cortante da Seção $D^{\text {dir }}$ do Exemplo 1 com o trem-tipo na posição crítica.

Figura 6.4 - Diferença entre a envoltória obtida e a envoltória real.

Figura 6.5 - Surgimento de falhas na envoltória de esforços cortantes no balanço. $\quad 97$

Figura 6.6 - Número de avaliações da função aptidão no Exemplo 1 x $\Delta . \quad 97$

Figura 6.7 - Variação do esforço cortante máximo na seção $B^{\text {dir }}$ do Exemplo 1 em função de $\Delta$.

Figura 6.8 - Envoltória de momento fletor do Exemplo 1 para $1+\lambda-E E$, $\mu+\lambda-E E$, Força Bruta e Cargas-em-picos.

Figura 6.9 - Falha na envoltória de momento fletor ao utilizar a

Estratégia $\mu+\lambda$.

Figura 6.10 - Exemplo 2.

Figura 6.11- Envoltória de esforço cortante do Exemplo 2 para $1+\lambda-E E$, $\mu+\lambda-E E$ e Força Bruta.

Figura 6.12 - Envoltória de esforço cortante do Exemplo 2 para Cargas-empicos.

Figura 6.13 - Envoltória de momento fletor do Exemplo 2 para $1+\lambda-E E$, $\mu+\lambda-E E$ e Força Bruta.

Figura 6.14 - Envoltória de momento fletor do Exemplo 2 para Cargas-em-picos.

Figura 6.15 - Exemplo 3.

Figura 6.16 - Envoltória de esforço normal do Exemplo 3 para $1+\lambda-E E$, $\mu+\lambda-E E$, Força Bruta e Cargas-em-picos.

Figura 6.17 - Envoltória de esforço cortante do Exemplo 3 para $1+\lambda-E E$, $\mu+\lambda-E E$, Força Bruta e Cargas-em-picos.

Figura 6.18 - Envoltória momento fletor do Exemplo 3 para $1+\lambda-E E$, $\mu+\lambda-E E$, Força Bruta e Cargas-em-picos.

Figura 6.19 - Exemplo 4.

Figura 6.20- Envoltória de esforço cortante do Exemplo 4 para $1+\lambda-E E$, $\mu+\lambda-E E$, Força Bruta e Cargas-em-picos.

Figura 6.21- Envoltória de momento fletor do Exemplo 4 para $1+\lambda-E E$, 
$\mu+\lambda-E E$, Força Bruta e Cargas-em-picos.

Figura 6.22- Trem-tipo do Caso 1.

Figura 6.23- Envoltória de esforço cortante no balanço da estrutura do Exemplo 4 utilizando o trem-tipo do Caso 1.

Figura 6.24- $L I$ de esforço cortante da seção $B^{\text {dir }}$ do Exemplo 3 com trem-tipo nas posições críticas.

Figura 6.25- Trem-tipo caso 2.

Figura 6.26- Envoltória de esforço cortante da estrutura do Exemplo 4 para o trem-tipo do Caso 2 utilizando $1+\lambda-E E$.

Figura 6.27- Envoltória de esforço cortante da estrutura do Exemplo 4 para o trem-tipo do Caso 2 utilizando Cargas-em-picos.

Figura 6.28- Número de avaliações da função aptidão na envoltória de esforço cortante máximo.

Figura 6.29- Tempo de processamento do programa para cálculo da envoltória de esforço cortante máximo. 


\section{Lista de quadros}

Quadro 4.1 - Botões de manipulação do trem-tipo. 64

Quadro 4.2 - Possíveis tipos de ocorrência de eventos. 74

Quadro 4.3- Botões para calcular a envoltória de esforços. 75 


\section{Lista de tabelas}

Tabela 2.1 - Envoltórias de Esforço Cortante [kN]. 31

Tabela 2.2 - Resultados obtidos na envoltória de momento fletor. 33

Tabela 3.1 - Comparação entre Estratégia Evolutiva e Algoritmo Genético 58

Tabela 4.1 - Cargas dos veículos (NBR - 7188, 1982). 60

Tabela 4.2 - Características dos veículos (NBR - 7188, 1982). 61

Tabela 4.3 - Cargas dos trens-tipo (NBR - 7189, 1985). 62

Tabela 5.1 -. Parâmetros adotados na $(\mu+\lambda)-E S$. 87

Tabela 6.1 - Resultados obtidos na envoltória de esforço cortante do

Exemplo 1.

Tabela 6.2 - Erros relativos na envoltória de esforço cortante do Exemplo 1.93

Tabela 6.3 - Número de avaliações da função aptidão no traçado da envoltória de esforço cortante do Exemplo 1.

Tabela 6.4 - Resultados obtidos na envoltória de momento fletor do

Exemplo 1.

Tabela 6.5 - Erros relativos na envoltória de momento fletor do Exemplo 1.99

Tabela 6.6 - Número de avaliações da função aptidão no traçado da envoltória de momento fletor do Exemplo 1.

Tabela 6.7 - Resultados obtidos na envoltória de esforço cortante do

Exemplo 2. 101

Tabela 6.8 - Erros relativos na envoltória de esforço cortante do Exemplo 2. 102

Tabela 6.9 - Número de avaliações da função aptidão no traçado da envoltória

de esforço cortante do Exemplo $2 . \quad 102$

Tabela 6.10 - Resultados obtidos na envoltória de momento fletor do

Exemplo 2.

Tabela 6.11 - Erros relativos na envoltória de momento fletor do Exemplo 2. 104

Tabela 6.12 - Número de avaliações da função aptidão no traçado da envoltória de momento fletor do Exemplo 2.

Tabela 6.13 - Resultados obtidos na envoltória de esforço normal na coluna do pórtico do Exemplo 3.

Tabela 6.14 - Erros relativos na envoltória de esforço normal na coluna do

pórtico do Exemplo $3 . \quad 106$

Tabela 6.15 - Número de avaliações da função aptidão no traçado da envoltória de esforço normal do Exemplo $3 . \quad 106$ 
Tabela 6.16 - Resultados obtidos na envoltória de esforços cortantes do Exemplo 3.

Tabela 6.17 - Erros relativos na envoltória de esforço cortante do Exemplo 3.107 Tabela 6.18 - Número de avaliações da função aptidão no traçado da envoltória

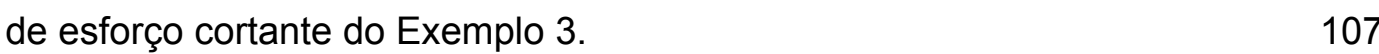
Tabela 6.19 - Resultados obtidos na envoltória de momento fletor do Exemplo 3.

Tabela 6.20 - Erros relativos na envoltória de momento fletor do Exemplo 3.

Tabela 6.21 - Número de avaliações da função aptidão no traçado da envoltória de momento fletor do exemplo 3.

Tabela 6.22 - Resultados obtidos na envoltória de esforço cortante do Exemplo 4.

Tabela 6.23 - Erros relativos na envoltória de esforço cortante do Exemplo 4.111 Tabela 6.24 - Número de avaliações da função aptidão no traçado da envoltória de esforço cortante do Exemplo 4.

Tabela 6.25 - Resultados obtidos na envoltória de momento fletor do Exemplo 4.

Tabela 6.26 - Erros relativos na envoltória de momento fletor do Exemplo 4. 112 Tabela 6.27 - Número de avaliações da função aptidão no traçado da envoltória de momento fletor do Exemplo 4. 


\section{Lista de Símbolos}

\section{Romanos}

$d x \quad$ Distância que a estrutura é discretizada

E Esforço ou reação

fd Função densidade

$g \quad$ Carga uniformemente distribuída

$i \quad$ Indica uma das variáveis da função objetivo

IND Índice fornecido pela decodificação da variável

$k \quad$ Número máximo de gerações que um indivíduo pode permanecer na população

$M_{S} \quad$ Momento fletor em $S$

n número de variáveis da função objetivo

na número de avaliações da função aptidão em uma seção transversal da estrutura

$n b \quad$ Número de bits

$n_{\text {ger }} \quad$ Número de gerações

$n_{\text {sec }} \quad$ Número de seções transversais que a estrutura foi discretizada

$n_{t o t} \quad$ Número total de avaliações da função aptidão em toda estrutura

$P \quad$ Carga concentrada

$p \quad$ Carga de multidão externa

$p^{\prime} \quad$ Carga de multidão interna

$p_{c} \quad$ Probabilidade de recombinação (crossover)

$p_{i} \quad$ Probabilidade de seleção

$p_{m} \quad$ Probabilidade de ocorrência de mutação de um gene

$q \quad$ Carregamento acidental de ocupação

$q \quad$ Carga distribuída correspondente ao vagão cheio no trem-tipo ferroviário

$q^{\prime} \quad$ Carga distribuída correspondente ao vagão vazio no trem-tipo ferroviário

$R \quad$ Reação de apoio

$S \quad$ Seção transversal da estrutura

$t$ Tamanho dos sub-grupos de torneios na $P E$ 


$\begin{array}{ll}u & \text { Variável aleatória uniforme } \\ v & \text { Indivíduo genitor } \\ v^{\prime} & \text { Indivíduo descendente } \\ x & \text { Ponto de busca no espaço } \\ x & \text { Posição da carga unitária no cálculo da linha de influência } \\ x & \text { Posição da carga concentrada do trem-tipo } \\ x a & \text { Posição inicial da carga distribuída do trem-tipo } \\ x b & \text { Posição final da carga distribuída do trem-tipo } \\ x^{L} & \text { Limite inferior do espaço de busca } \\ x^{U} & \text { Limite superior do espaço de busca } \\ z & \text { Variável aleatória normal padrão } \\ l & \text { comprimento do caminho que o trem-tipo irá percorrer } \\ l_{t} & \text { comprimento do trem-tipo } \\ l_{t o t} & \text { Comprimento total da estrutura }\end{array}$

\section{Gregos}

$\alpha$

Média

$\Delta$

Deslocamento generalizado

$\lambda$

Número de descendentes

$\mu$

Número de genitores

$\theta$

Rotação

$\rho \quad$ Número de indivíduos que participam da recombinação

$\sigma \quad$ Desvio padrão

$\sigma^{2} \quad$ Variância

$\tau \quad$ Parâmetro da Estratégia Evolutiva

$\tau^{\prime} \quad$ Parâmetro da Estratégia Evolutiva 


\section{Lista de Abreviaturas}

$\begin{array}{ll}A E & \text { Algoritmo Evolucionário } \\ A G & \text { Algoritmo Genético } \\ E E & \text { Estratégia Evolutiva } \\ \text { FTOOL } & \text { Two-dimensional Frame Analysis Tool } \\ L I & \text { Linha de influência } \\ L I M & \text { Linha de influência de momento fletor } \\ L I Q & \text { Linha de influência de esforço cortante } \\ P D V & \text { Princípio dos deslocamentos virtuais } \\ P E & \text { Programação Evolutiva } \\ P G & \text { Programação Genética } \\ \text { v.a. } & \text { Variável aleatória }\end{array}$

